\title{
ESTIMATING POTENTIAL OUTPUT AND \\ CAPACITY UTILISATION FOR THE SOUTH AFRICAN ECONOMY
}

\author{
CHARLOTTE DU TOIT AND ELNA MOOLMAN
}

AN ASPECT THAT DESERVES CONSIDERABLE attention in supply-side modelling is the development of some measure for potential output. Measuring productive potential and the deviation between potential and actual output (i.e. the output gap) provides a number of key insights into macroeconomic performance.

Output in general is determined by the quantity and quality of the various factors of production and their productivity. Potential output is an indication of the aggregate supply capabilities of the economy and embodies information about developments in the stock of capital, the labour force and technical change. The actual level of output on the other hand, is also influenced by the demand for goods and services. Deviations between the potential and actual levels of output, designated as the output gap, thus provide a measure of the capacity utilisation of the economy and to the extent that demand factors are incorporated, a measure of relative supply and demand in the economy at a particular time. As such, it contains useful short-term information for the formulation of economic policy, particularly policies aimed at controlling inflation. Over the medium term, the growth rate of potential output provides a useful guide for the assessment of sustainable non-inflationary growth in output and employment. Therefore, in a macro-econometric context, capacity utilisation (or the output gap) serves as a determinant of the behaviour of prices and wages and influences all key macroeconomic variables through a well-developed supply system.

However, modelling the output gap or capacity utilisation is a complicated matter for a number of reasons. First, different concepts 
of potential output have been proposed in the literature and are used in different models. Second, a wide variety of empirical methods are used to measure potential output, ranging from time-series and trendtype analyses to production function-based methodologies, with the precise results sensitive to the method chosen. Finally, actual output could be determined directly from Keynesian demand analysis or by using a production function (supply) approach.

This paper proceeds as follows: in the next section, the theoretical methodologies and concepts are presented; in section 2 the different methods of estimating potential output and output gaps are explained; and in section 3 the empirical results are presented.

\section{DIFFERENT CONCEPTS AND METHODOLOGIES}

The concept of "potential output" is not well defined in the literature and has seen different applications in production analyses. Does "potential" refer to the maximum attainable level of production such as has been demonstrated at peak periods in the past, or does it refer to a sustainable level of production in the sense that production can continue at this level without major constraints developing?

It appears from the literature (Laxton and Tetlow 1992) that the concept of potential output has evolved from one that focused on the maximum possible output to the currently preferred definition of ".. .the level of goods and services that an economy can supply without putting pressure on the rate of inflation" (Conway and Hunt 1997:2). This development coincided with a change from the view that the supply of goods (and thus potential output) is an essentially deterministic process to one that regards supply as a stochastic phenomenon. 
In a recent review of the concepts of potential output, Scacciavillani and Swagel (1999) summarise the literature as follows:

Broadly speaking the literature distinguishes between two definitions. In the first, more along the Keynesian tradition, the business cycle results primarily from movements in aggregate demand in relation to a slow moving level of aggregate supply. In business cycle downswings, there exist factors of production that are not fully employed. In the second approach - more along the neoclassical tradition - potential output is driven by exogenous productivity shocks to aggregate supply that determine both the long-run growth trend and, to a large extent, short-term fluctuations in output over the business cycle.... Unlike the Keynesian framework where the economy might reach potential only after an extended period, potential output in the neoclassical framework is synonymous with the trend growth rate of actual output. The key measurement problem is thus to distinguish between permanent movements in potential output and transitory movements around potential.

The methodologies employed in measuring potential output and its deviation from actual output (i.e. the output gap) are not necessarily divided neatly into the above two intellectual frameworks.

In early applications, potential output was treated as a deterministic process. The essence of this approach is that "potential" refers to the maximum attainable level of output without taking the sustainability of growth in production into account (Burrows and Smit 1999). An example is the trends-through-peaks method developed by Lawrence Klein at the Wharton School.

The stochastic or economic approach is based on the use of a production function to determine potential output. This approach has been widely used, also by institutions such as the OECD (Giorno et al. 1995). The production function approach can be implemented with varying degrees of sophistication and detail. Examples are the relatively simple Cobb-Douglas function estimated on the basis of factor income shares (Scacciavillani and Swage 1999), CES production functions estimated for the OECD Interlink country model (Torres and Martin 1993; Giorno et al. 1995), and the Coen-Hickman (1995) annual growth model of the U.S. economy endogenising the natural rate of unemployment, the potential labour force and the potential average hours of work.

A distinction between "potential" and "normal" output needs to be made within the stochastic production function-based framework. 
Modelling potential output as opposed to normal output requires the estimation of potential levels of factor inputs. "Normal" output, defined as the production level with the current quantities of factor inputs and operating at a "normal" or trend rate of utilisation, is usually obtained by smoothing the various components of the production function (Turner et al. 1996).

The statistical or time-series approach to determining potential output as an exogenous trend variable, developed when economists started to question the notion that potential output changed deterministically over time. The supply shocks of the 1970s and the publication of the influential paper by Nelson and Plosser (1982) suggesting that output series are best characterised as integrated series, led to a change in focus on stochastic trends. This implied that determining potential output requires techniques that could distinguish between permanent and temporary movements in total output. A number of techniques have been developed for this purpose (Burrows and Smit 1999).

Two important and commonly used measures can therefore be identified. The first uses measures of potential output that are structural and depend on a production function framework, incorporating information concerning the capital stock, working population, trend participation rates, structural unemployment and factor productivity developments. Specific attention may also be given to the sustainability of non-inflationary growth associated with the labour market, in which case information about both actual rates and underlying natural rates of unemployment is utilised (i.e. the non-accelerating wage rate of unemployment, or NAWRU).

A second set of measures is derived by applying time-series analysis and methods to actual changes in real GDP. Though parsimonious in the use of information, these methods are mechanical and have difficulty in dealing with frequent structural changes. They therefore require ad hoc judgements about the current cycle in order to keep the results within reasonable bounds. 


\section{ESTIMATING POTENTIAL OUTPUT AND OUTPUT GAPS}

A variety of methods can be used to determine trend or potential output and a corresponding output gap. They can be divided into two broad groups, i.e. time-series (mostly smoothing) techniques and structural production function techniques. The techniques most commonly used in empirical analysis are firstly the Hodrick-Prescott (1997) filter, a time-series method, and secondly the estimation of potential output, a structural approach based on a production function relationship. The latter approach requires more data and more assumptions about economic interrelationships, but is less mechanical and more directly relevant to macroeconomic assessment. These two approaches will now be discussed.

(a) Si time-series approach: smoothing actual output using a HodrickPrescottfilter

The gross domestic output (GDP) smoothing approach using a Hodrick-Prescott (HP) filter fits a trend through all the observations of real GDP, regardless of any structural breaks that might have occurred, by allowing the regression coefficients themselves to vary over time. This is done by finding a trend output that simultaneously minimises a weighted average of the gap between output and trend output, at any given time, and the rate of change in trend output at that point in time. The HP filter is a two-side linear filter that estimates the trend $\mathrm{Y}^{*}$ for $\mathrm{t}$ $=1,2, \ldots$. T to minimise

$$
\sum_{t=1}^{T}\left(\ln Y_{t}-\ln Y_{t}^{*}\right)^{2}+\lambda \sum_{t=2}^{T-1}\left[\left(\ln Y_{t+1}^{*}-\ln Y_{t}^{*}\right)-\left(\ln Y_{t}^{*}-\ln Y_{t-1}^{*}\right)\right]^{2}
$$

where $\lambda$ is the weighting factor that controls the smoothness of the

1 See Canova (1993) for a number of other possible approaches. 
resulting trend line. A low value of $\lambda$ will produce a trend that follows actual output more closely, whereas a high value of $\lambda$ reduces sensitivity of the trend to short-term fluctuations in the actual series and, in the limit, the trend tends to the mean growth rate for the whole estimation period.

The mechanical nature of a filter such as the HP filter, requiring only actual values for GDP, has the advantage of being a fairly straightforward and simple technique to perform. However, some points of criticism have been raised against the HP filter.

(i) A major point of criticism is the arbitrary choice of $\lambda$ which determines the variance of the trend output estimate. Specifically, the variance of trend output falls as $\lambda$ increases, whilst the amplitude of the corresponding output gap increases with $\lambda$ (increasing). From a statistical point of view, $\lambda$ must be arbitrarily chosen. The reason is that any non-stationary series (integrated of order 1) can be decomposed into a non-stationary trend and stationary cycle combinations. Thus far, no satisfactory statistical criterion has been developed for the optimal choice of trend/cycle decompositions.

However, Hodrick and Prescott proposed setting $\lambda$ equal to 100 , 1600 and 14400 for annual, quarterly and monthly data respectively. These values seem to have become the standard for many applications in literature. ${ }^{2}$

Since the choice of $\lambda$ remains arbitrary, Giorno et al. (1995) identified the following possible criteria. The first approach would be to follow Hodrick and Prescott's approach and choose a constant ratio of the variance of trend and actual output, i.e. choose a $\lambda$ consistent with the degree of fluctuation in the actual GDP time series. This means that $\lambda$ would be chosen to generate greater variance (fluctuation) in trend for an actual GDP that is fluctuating more. A second approach is to choose a value for $\lambda$ that generates a pattern of cycles that is

\footnotetext{
2 Canova (1993) discusses the problems arising from the indiscriminate use of these values for $\lambda$ for GDP and other data series.
} 
broadly consistent with a priori information about past cycles in the GDP. This approach is both judgmental and less transparent than the first criterion.

(ii) Another criticism is that the accuracy of the HP filter deteriorates near the end of the sample - referred to as an end-point problem. The reason for this is that a trend line is fitted symmetrically through the data. If the beginning and the end of the data set do not reflect similar points in the cycle, then the trend will be pulled upwards or downwards towards the path of actual output for the first few and the last few observations. For example, for a country that is slower to emerge from a recession, a HP filter will tend to under-estimate trend output growth for the current period. Using projections, which go beyond the short-term to the end of the current cycle, can reduce this problem and give more stability to estimates for the current and short-term projections period. Again this is arbitrary in the sense that specific weights are assigned to judgements about potential and output gaps embodied in the projection. The HP filter estimates will tend towards potential, providing the output gap is closed by the end of the extended sample period.

(Hi) A further weakness of the method is the treatment of structural breaks, which are typically smoothed over by the HP filter. The break is moderated when it occurs and its effects are spread out over several years, depending on the value of $\lambda$. This is especially problematic in the case where the break results in large discrete changes in output levels.

\section{(b) Structural production function approach: estimating potential output}

From the point of view of macroeconomic analysis, the most important limitation of any smoothing method is that it is largely mechanistic and ignores all structural properties associated with production. Aspects such as the availability and quality of factors of production, their productivity, the production technology and technical progress, and all other exogenous influences, are not taken into account. The trend output growth projected by time- series methods may be inconsistent (too high or too low) with what is known or being assumed about the growth in capital, labour supply or factor productivity. The trend growth may also be unsustainable because of the ignored inflationary 
pressures.

A structural production function approach therefore has the advantages of overcoming the above-mentioned shortcomings, incorporating the role of demand pressure on employment and inflation and allowing for consistent judgement on some of the key elements. The production function approach explicitly models a production technology in terms of factor inputs, factor technology and to some extent the role of technical progress. Potential output is then determined as the level of output that results when the factors of production and total factor productivity are at their "potential" levels. The output gap (capacity utilisation) is calculated as the ratio between the potential and actual levels of output.

The production function may be represented by:

$Y_{t}=A_{t} * F\left(K_{t}, L_{t}\right)$

with

$Y_{t}=$ output

$A_{t}=$ technical progress (including factor productivity)

$K_{t}=$ capital stock

$L_{t}=$ employment

$F=$ the assumed production technology, e.g. Cobb-Douglas, CES, etc.

Technical progress $\left(A_{t}\right)$ may be Hicks-neutral, Harrod-neutral or even endogenous in nature incorporating factor productivity.

Potential output $Y_{t}^{*}$ is then generated by:

$Y_{t}^{* *}=A_{t}^{* *} * F\left(K_{t}^{*}, L_{t}^{*}\right)$

with

\footnotetext{
${ }^{3}$ Capacity utilisation or output gap is determined as the difference between potential
} and actual output if the logarithmic forms of the variables are used. 


$$
\begin{aligned}
& A_{t}^{*}=\text { "potential" technical progress } \\
& K_{t}^{*}=\text { "potential" capital stock } \\
& L_{t}^{*}=\text { "potential" employment }
\end{aligned}
$$

The potential levels of A, K and L may be determined in different ways. If "potential" is to designate the maximum output levels, then some measure of the maximum attainable levels of $\mathrm{A}, \mathrm{K}$ and $\mathrm{L}$ must be provided. Depending on the purpose of estimation and the definition applied, variations on these potential levels may occur. For example, if potential output is defined as the maximum level of output consistent with stable inflation, a measure such as the non-accelerating wage rate of unemployment (NAWRU) needs to be included in the specification of potential employment $\left(L_{t}^{*}\right){ }^{4}$ Should potential be defined as the "trend" or "normal" levels of factor utilisation, a time-series measure such as the Hodrick-Prescott filter may be used.

\section{EMPIRICAL ESTIMATES OF POTENTIAL OUTPUT AND CAPACITY UTILISATION}

\section{(a) The methodology}

The particular concept of potential output selected for the purpose of modelling the supply-side of the South African economy, refers to the maximum level of output that is consistent with stable inflation. Capacity utilisation is therefore defined as the ratio between actual production (production function-based) and potential, not normal output, incorporating the role of the non-accelerating wage rate of unemployment (NAWRU). This particular concept was chosen in line with the emphasis on control of inflation as a key medium-term priority. In addition, its use ensures consistency between labour market equilibrium and product market equilibrium in the supplyside model.

4 This technique was utilised by the OECD in the measuring of potential output and output gaps in the seven major OECD countries (Torres et al. 1989 and Giorno et al. 1995)

5 This technique was employed by the OECD in the modelling of the supply-side of the seven major OECD economies (Turner et al. 1996) 


\section{(b) The analytical framework}

The estimation of potential output for South Africa is based on a structural production-function relationship, with the maximum level of output consistent with stable inflation. The level of unemployment and its associated non-accelerating wage rate are incorporated in the estimation of potential employment. This approach was adopted from the OECD.

The estimated production function for South Africa has proven to be of the Cobb-Douglas kind and is represented by the following expression:

$Y=A_{0} e^{\delta T} K^{\alpha} N^{\beta}$

$\mathrm{n}$ logarithmic form:

$y=a_{0}+\delta T+\alpha k+\beta n$

with

$Y=$ actual gross domestic product at factor cost

$A_{0}=$ Hicks-neutral technology component

$N=$ actual employment

$K=$ actual capital stock

$T=$ endogenous technical progress or technology (including factor productivity)

$\alpha=$ labour share parameter

$\beta=$ capital share parameter

6 This approach was specifically followed on two occasions: "Measuring potential output in the seven major OECD countries" (Torres et al. 1989) and "Estimating potential output, output gaps and structural budget balances" (Giorno et al. 1995).

See Du Toit (1999), as well as Du Toit and De Wet (2002) for the results of the estimation of a neo-classical production function for the South African economy, where it has been proven and tested empirically that the South African economy's production structure may be represented by a CobbDouglas production function. 


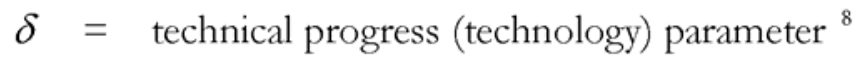

$(\alpha+\beta)<1$; exhibiting decreasing returns to scale technology.

Potential output is determined by substituting trend technology $\left(T^{*}\right)$, actual capital stock $(k)$ and potential employment $\left(n^{*}\right)$ back

into the estimated production function:

$y^{*}=a_{0}+\delta T^{*}+\alpha k+\beta n^{*}$

where $T^{*}$ is determined by smoothing technology using a HodrickPrescott filter $(\lambda=100)$.

The measure of potential employment is defined as the level of labour resources that might be employed without resulting in additional inflation. This amounts to adjusting the actual labour input used in the estimated production function for the gap between actual unemployment and the estimated non-accelerating wage rate of unemployment (NAWRU).

The level of potential employment $\left(N^{*}\right)$ is calculated as:

$$
N^{*}=\operatorname{LFS}(1-\mathrm{NAWRU})
$$

where LFS is the smoothed labour force (the product of the working age population and the trend participation rate), and NAWRU is the estimated non-accelerating wage rate of unemployment

The method adopted to measure the NAWRU essentially assumes that the change in wage inflation is proportional to the gap

\footnotetext{
$8 \quad$ See Du Toit (1999), as well as Du Toit and De Wet (2002) for the results of the estimation of a neo-classical production function for the South African economy, where a full exposition (theoretical and empirical) is given of the construction of the technical progress variable.

Capacity utilisation, a short-run variable in nature, acts as a supply-side constraint via its effect on prices. In estimating potential output with the primary purpose of determining the associated output gap for one reason, it is necessary to use the actual level of capital since it represents a relative binding physical constraint on supply in the short to medium term.

10 See Pichelmann and Schuh (1997) for an exposition on the basic theory and empirical estimation of the NAWRU.
} 
between actual unemployment and the NAWRU. Assuming also that the NAWRU changes only gradually over time, ${ }^{12}$ successive observations of the changes in inflation and actual unemployment rates can then be used to calculate a time series corresponding to the implicit value of the NAWRU. More specifically, it is assumed that the rate of change of wage inflation is proportional to the gap between actual unemployment and the NAWRU, thus:

$$
D^{2} \log W=-a(U-N A W R U), \quad a>0
$$

where $D$ is the first-difference operator and $W$ and $U$ are the real wage and unemployment rates, respectively. Assuming the NAWRU to be constant between any two consecutive time periods, an estimate of $a$ can be calculated as:

$$
a=-\left(D^{3} \log W\right) / D U
$$

which, in turn, is used to give the estimated NAWRU as:

$$
N A W R U=U-\left(D U / D^{3} \log W\right) D^{2} \log W
$$

The resulting NAWRU series is then smoothed, again using a HodrickPrescott filter to eliminate erratic movements. The information utilised in the above expression for the NAWRU is endogenised. Both the unemployment and the real wage rates result from a consistent neoclassical labour model, which in turn forms part of a supply-side model for South Africa where prices are also endogenously determined by the system as a whole. This measure for the NAWRU can therefore be classified as a wage-price model approach.

\footnotetext{
11 This method is described by Elmeskov and MacFarlan (1993).

12 This is based on the assumption of partial hysteresis: actual unemployment feeds only partly into future equilibrium unemployment. In this case unemployment evolves only slowly towards its steady-state level. In such a situation, the short-run NAWRU - meaning the level of unemployment at which there is no current upwards or downwards pressure on inflation - always lies between steady-state equilibrium unemployment and last period's actual unemployment. This carries the implication that high unemployment can only be slowly reduced to its long-run equilibrium level if temporary increases in inflationary pressures are to be avoided (Pichelmann and Schuh 1997:8).
} 


\section{(c) The estimation results}

(i) Estimation of the South African NAWRU

The estimate for the NAWRU of the South African economy is given by Fig. 1. It is increasing at a steady rate, suggesting severe structural problems in the economy as a whole and the labour market in particular.

The results imply that an "equilibrium" rate of unemployment and therefore a unique long-run NAWRU to which the unemployment reverts in the long run does not exist. This is in line with a growing number of empirical studies (Pichelmann and Schuh 1997) that suggest that the equilibrium unemployment rate may be described by a non-stationary time-series, incorporating both a deterministic and stochastic trend component.

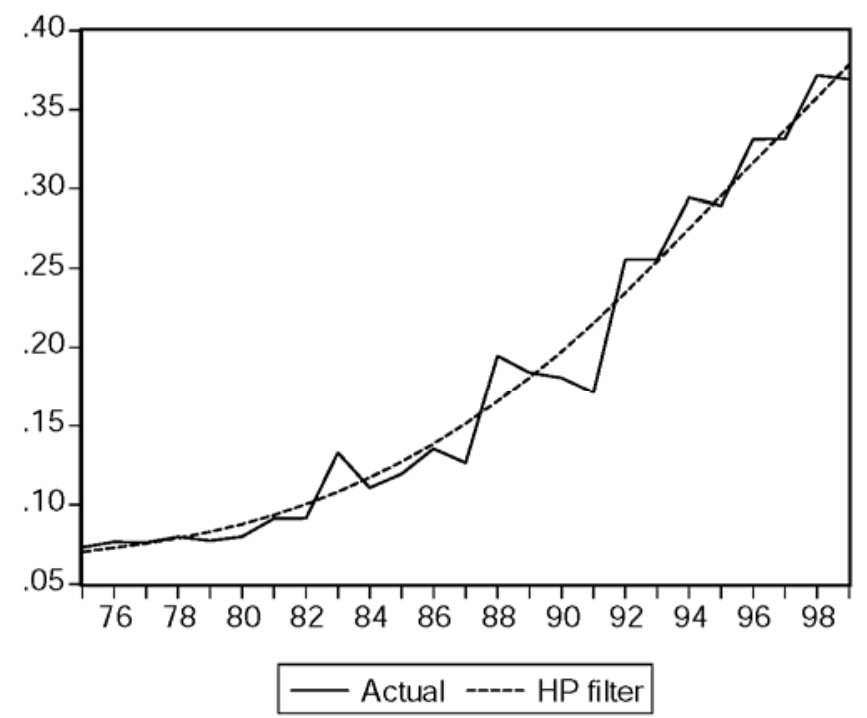

Figure 1. South African NAWRU

This increasing rate is attributed to the hysteresis nature of unemployment in South Africa, which in turn is based on the

\footnotetext{
${ }^{13}$ Unemployment is strongly dependent on its own history (Pichelmann and Schuh,
} 1997:7). 
behaviour of labour market participants, changes in their productive capacity caused by unemployment and the resulting consequences for wage bargaining, and the matching process between workers and jobs. The general idea is that a distinction be drawn between insiders and outsiders in the labour market and that they carry different weights in the wage bargaining process. When unemployment by itself tends to reinforce the outsider status of those affected, then the moderating impact of higher unemployment on wages will vanish over time. The same result will emerge when the (employed) insiders have sufficient market power, probably fostered by employment protection regulations, to safeguard their income claims and employment status against outside labour market conditions. Finally, a growing number of unemployed outsiders may create information distortions in the labour market, thereby making it more difficult to form suitable matches between workers' characteristics and the skill requirements of potentially available jobs.

A number of hysteresis-mechanisms, ${ }^{14}$ which could lead to permanent shifts in equilibrium unemployment over time, have been identified. The most suitable mechanism to explain the South African situation, operates through changes in human capital. According to this view, prolonged periods of unemployment may lead to a deterioration of skills and important attitudinal aspects of the work ethics and motivation of individual job seekers. And, when out of work, there are no opportunities for learning-by doing and on-the-job training. The loss of skills during unemployment may also lead to duration dependence in the probability of leaving unemployment, i.e. the likelihood that unemployed workers move to employment is likely to fall as the duration of unemployment increases. Furthermore, discouragement effects may over time loosen the attachment to the work force resulting in reduced job search intensities.

14 Pichelmann and Schuh (1997) present a theoretical model in explaining the occurrence and effects (supply- and demand-side effects) of hysteresis on the equilibrium level of unemployment. 
Even when the quantitative importance of human capital depreciation is considered to be fairly small, the mere fact of being out of work for a long time may convey a negative signal about workers' productivity to potential employers. Consequently, the longterm unemployed may over time receive fewer and fewer job offers and may, finally, even be regarded as "unemployable". The resulting detachment from the labour market implies that the long-term unemployed may exert little or no downward pressure on wage increases. Moreover, a growing number of unsuccessful job seekers in the pool of the unemployed may reduce the speed by which vacant jobs can be filled by suitable candidates.

When specific skills are an important aspect of the employment relation, involuntary separation from a job may imply long waiting periods for re-employment; and when the loss of specific skills and the associated wage premium eventually has to be accepted, specific capital no longer provides a buffer between productivity and the value of employment elsewhere or non-employment, so turnover from new jobs, probably associated with recurrent unemployment, may be rapid.

Another strand of reasoning emphasises the wage-bargaining behaviour of the employed insiders and the role of adjustment costs. For example, when unions bargain mainly on behalf of the incumbent workforce, a temporary adverse shock to employment will tend to perpetuate itself, because real wage demand is adapted to the now smaller number of employed insiders. Generally speaking, shifts in the employment composition in favour of groups facing little risk of unemployment may affect the overall bargaining stance of unions and thus reduce the wage-moderating impact of a given rate of unemployment.

For insider effects to persist, the employed insiders must command some degree of market power. This could stem from several sources such as training costs or statutory seniority systems, but also from various forms of job security legislation. While the resulting reduction in turnover may well be in the interest of both the firm and the workers, the crucial point with regard to the persistence 
issue is that turnover costs render it difficult for outsiders to effectively compete for jobs.

In addition to the supply-side mechanisms described above there may also be a number of important demand-side effects which could lead to an adjustment in equilibrium unemployment. A number of possible "price push" factors may cause product demand changes to impact on equilibrium unemployment. Some of these are wage-price stickiness (the traditional Keynesian argument), changes in the marginal product of inputs, competitive interaction between firms, changes in the real user-cost-of-capital and changes in the composition of demand (Pichelmann and Schuh 1997).

(ii) Potential output and output gap (capacity utilisation) for South Africa A structural approach, based on the estimated production function for South Africa, is used to estimate potential output. Potential output is defined here as the maximum level of output consistent with stable inflation. Potential output is therefore dependent on the actual level of the capital stock (serving as a shortrun supply constraint), potential employment and the trend in technical progress. Potential employment is estimated by taking into account the relationship between unemployment and wage/price inflation as embodied in wage-price blocks in the supply-side model of the South African economy. Consistency between labour market equilibrium and product market equilibrium is ensured by incorporating the NAWRU in the definition of potential output.

A comparison of growth rates and output gaps of estimated potential output and HP trend estimates are provided in Figs. 2 and 3 and Table 1. An important feature of the estimation results is that potential output growth rates fluctuate from year to year, more so than trend growth rates derived from output smoothing (using the HodrickPrescott filter). Although more factors could be ascribed to this higher degree of variance, the most important reasons are the growth in capital stock and variations in the NAWRU.

The results obtained for potential output based on the 
structural production function approach indicate that the South African potential to grow is deteriorating (see Fig. 2). This seems plausible due to the huge constraint posed by rising labour cost (see Fig. 4) and the resulting continuous increase in unemployment (see Fig. 5).

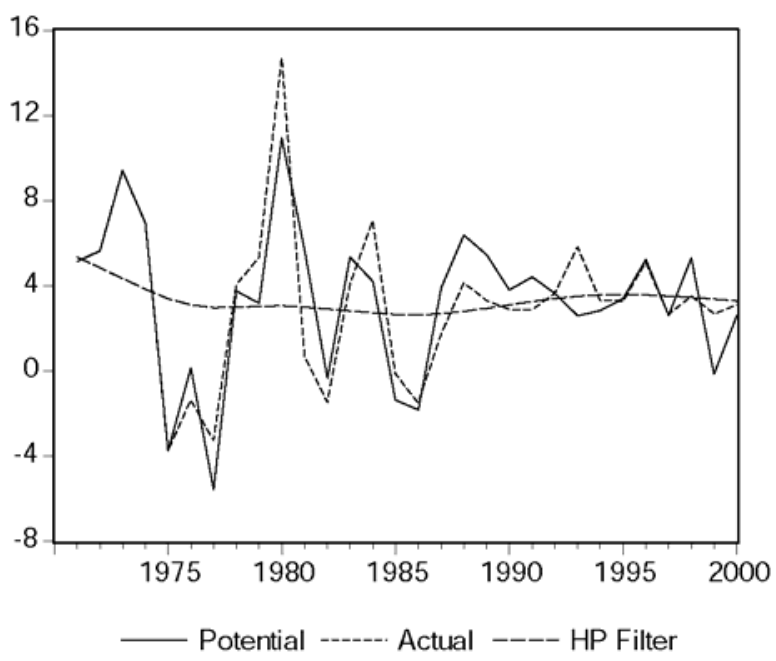

Figure 2. Output growth

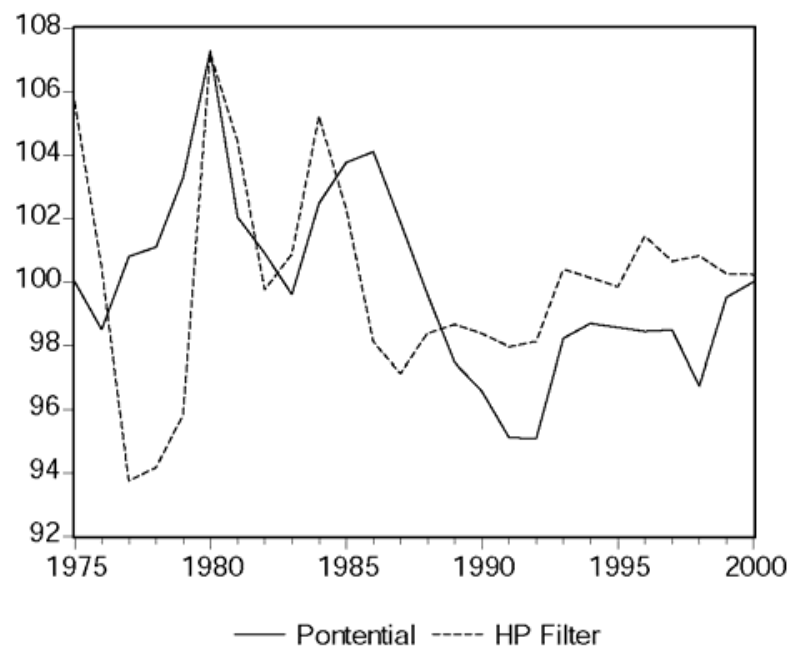

Figure 3. Output gap (capacity utilisation) 
This declining rate of employment is of both a structural and a cyclical nature. A significant part (the major portion) of the South African labour force is unskilled (see Fig. 6) and unskilled labour is increasingly expensive relative to skilled labour (see Fig. 7).

Table 1. Growth rates and output gaps under different methods

\begin{tabular}{|c|c|c|c|c|c|}
\hline & \multicolumn{3}{|c|}{ Growth Rate } & \multicolumn{2}{|c|}{ Output Gap } \\
\hline & Actual & $H P$ & Potential & $H P$ & Potential \\
\hline 1975 & -3.7308 & 0.000 & -3.7308 & 100.00 & 105.67 \\
\hline 1976 & -1.3590 & 3.7258 & 0.1583 & 98.494 & 100.44 \\
\hline 1977 & -3.2447 & 3.6447 & -5.5550 & 100.80 & 93.749 \\
\hline 1978 & 4.0607 & 3.6222 & 3.7660 & 101.09 & 94.161 \\
\hline 1979 & 5.3411 & 3.5924 & 3.1830 & 103.30 & 95.822 \\
\hline 1980 & 14.725 & 3.5019 & 10.941 & 107.28 & 107.20 \\
\hline 1981 & 0.6973 & 3.3197 & 5.7140 & 102.03 & 104.43 \\
\hline 1982 & -1.4578 & 3.1254 & -0.3360 & 100.90 & 99.750 \\
\hline 1983 & 4.0672 & 2.9619 & 5.3550 & 99.600 & 100.86 \\
\hline 1984 & 7.0632 & 2.8235 & 4.2090 & 102.49 & 105.23 \\
\hline 1985 & -0.1154 & 2.7155 & -1.3540 & 103.77 & 102.29 \\
\hline 1986 & -1.4926 & 2.6844 & -1.8140 & 104.10 & 98.105 \\
\hline 1987 & 1.7421 & 2.7439 & 3.9180 & 101.86 & 97.127 \\
\hline 1988 & 4.1404 & 2.8663 & 6.3920 & 99.591 & 98.372 \\
\hline 1989 & 3.3028 & 3.0169 & 5.4630 & 97.463 & 98.654 \\
\hline 1990 & 2.8889 & 3.1757 & 3.8070 & 96.573 & 98.371 \\
\hline 1991 & 2.8900 & 3.3275 & 4.4220 & 95.104 & 97.942 \\
\hline 1992 & 3.6406 & 3.4563 & 3.6600 & 95.086 & 98.123 \\
\hline 1993 & 5.8284 & 3.5444 & 2.5890 & 98.216 & 100.39 \\
\hline 1994 & 3.3141 & 3.5787 & 2.8420 & 98.681 & 100.12 \\
\hline 1995 & 3.2797 & 3.5695 & 3.4020 & 98.560 & 99,834 \\
\hline 1996 & 5.1143 & 3.5236 & 5.2410 & 98.436 & 101.44 \\
\hline 1997 & 2.6556 & 3.4445 & 2.6140 & 98.476 & 100.64 \\
\hline 1998 & 3.5229 & 3.3500 & 5.3040 & 96.738 & 100.81 \\
\hline 1999 & 2.6838 & 3.2485 & -0.1380 & 99.506 & 100.24 \\
\hline 2000 & 3.1259 & 3.1485 & 2.6312 & 100.00 & 100.22 \\
\hline
\end{tabular}

Apart from the fact that a significant component of unemployment in South Africa is structural in nature, the growth in GDP (see Fig. 2) has been inadequate to create sufficient job opportunities to alleviate the unemployment problem. The period of economic sanctions and disinvestments, resulting in the outflow of skilled labour (referred to as the "brain-drain") and other consequences, has only intensified the problem. 

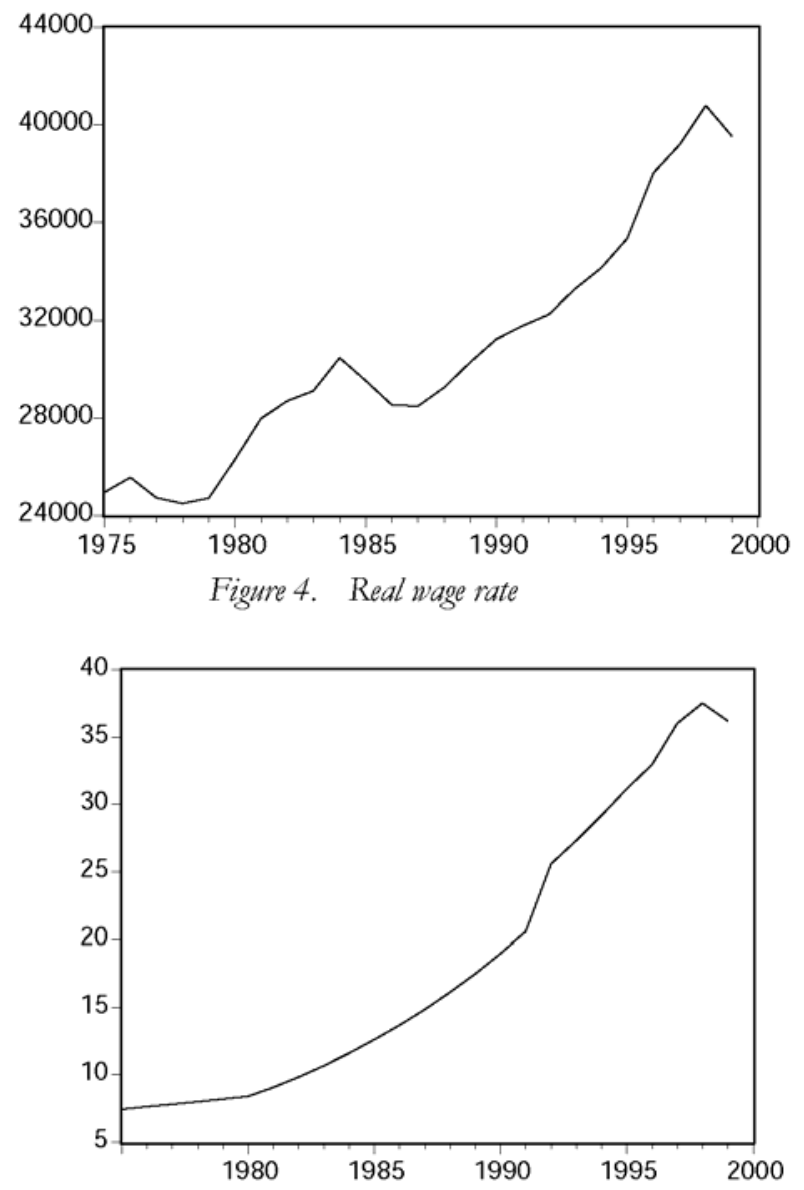

Figure 5. Unemployment rate

The time-series approach where output is smoothed by using the Hodrick-Prescott filter is clearly not taking the effect of these severe structural deficiencies in the South African economy into account. The advantage though of the HP-smoothed GDP is that it provides a check on the level and trend of the NAWRU. Although the structural estimation of potential output is sensitive to the specification of the NAWRU, which in turn is subjected to a range of possible measurement problems, the preferred approach is still to use the 
potential measure, provided that its plausibility is checked against a suitable time-series estimate of trend GDP.

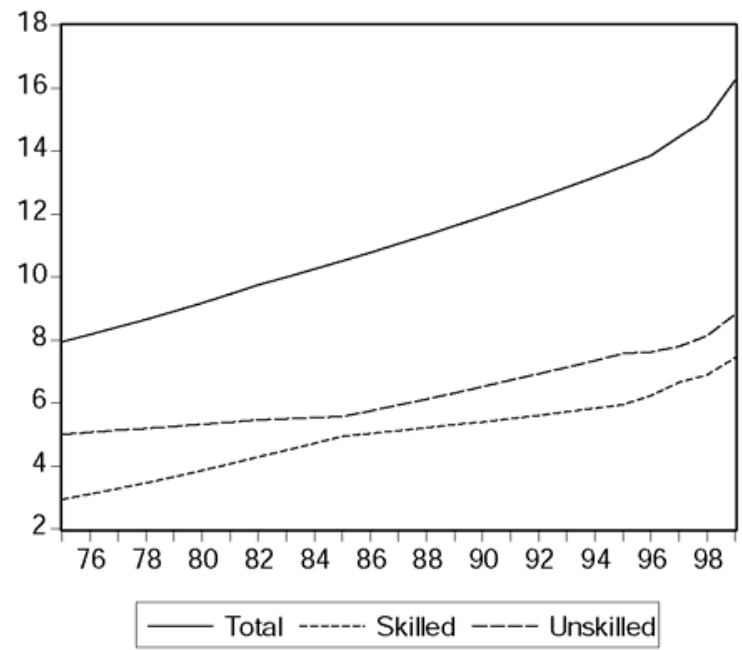

Figure 6. Total, skilled and unskilled labour supply

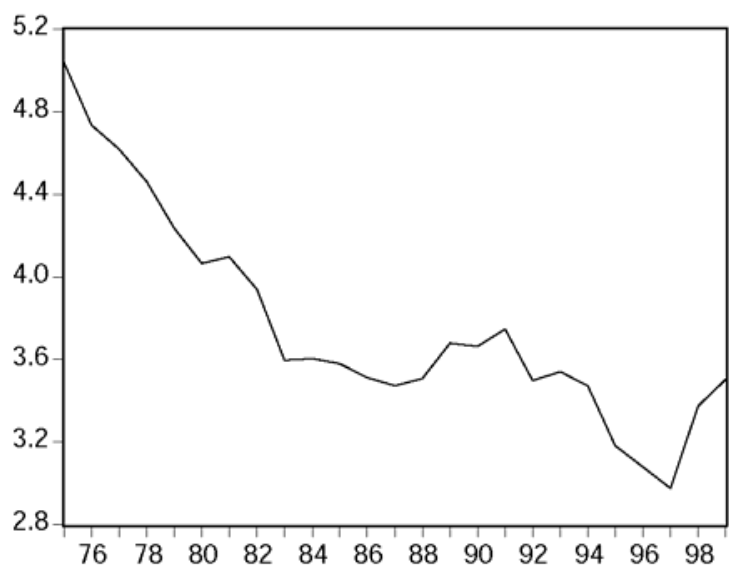

Figure 7. Skilled/Unskilled wage rate

\section{CONCLUSION}

In this study a measure for potential output and an associated output gap (capacity utilisation) were determined with the objective of incorporating them in an extended supply-side model of the South 
African economy. Two measures for potential output and their associated output gaps are determined. First, normal or trend output is obtained by smoothing actual GDP, using the Hodrick-Prescott filter. Second, potential output is estimated by using an estimated production function for the South African economy. Potential output is estimated by substituting trend technology, actual capital stock and potential employment into the Cobb-Douglas estimated production function (Du Toit 1999).

Trend technology is obtained by smoothing the endogenously determined technical progress variable (technology index) by applying the Hodrick-Prescott filter. Potential employment is estimated by adjusting the actual labour input in the estimated production function for the gap between actual unemployment and the estimated non-accelerating wage rate of unemployment (NAWRU). The method adopted to measure the NAWRU is based on the assumption that the change in wage inflation is proportional to the gap between actual unemployment and the NAWRU.

The estimation results obtained for the potential output and associated output gap seem plausible given the structural properties and history of the South African economy. The Hodrick-Prescott filter smoothed GDP serves as a check for the level and trend in potential output, but cannot be used in the structural supply-side model due to its mechanistic nature. Therefore, based on the structural nature of the analysis, the preferred measure identified is one based on a production function approach which takes explicit account of structural information, in particular with respect to the NAWRU.

The obtained results for potential output suggested a number of impediments in the South African economy - the South African potential to grow is seemingly deteriorating. This could be attributed to the sizeable constraint posed by rising labour cost and the resulting continuous increase in unemployment. This declining rate of employment can be perceived as both structural and cyclical in nature. A significant part of the South African labour force is unskilled which has been proven to be increasingly expensive relative to skilled labour. This, against the background 
that the international tendency towards capital-intensive production requires more capital, skilled labour and less unskilled workers, has aggravated the unemployment problem. Apart from the structural component of unemployment, the growth in GDP has failed, on its own, to create sufficient job opportunities to cure the unemployment problem. The period of economic sanctions and disinvestment, resulting in the outflow of skilled labour and other consequences, has most probably aggravated the problem.

\section{REFERENCES}

BURROWS, L. AND B.W. SMIT, (1999). Estimating Potential Output and Output Gaps for tbe South African Economy. Paper presented at the Biennial Conference of the Economic Society of South Africa, September 1999, Pretoria.

CANOVA, F., (1993). Detrending and Business Cycle Facts. CEPR Discussion Paper, No. 782.

COEN, R.M. AND B.G. HICKMAN, (1995). A Stochastic Model of Potential Output. Paper presented at Project LINK, September 1995, Pretoria.

CONWAY, P. AND B. HUNT, (1997). Estimating Potential Output: A Semi-Structural Approach. Discussion Paper, No. G97/9. Wellington: Bank of New Zealand.

COTÉ, D. AND D. HOSTLAND, (1996). An Econometric Examination of the Trend Unemployment Rate in Canada. Working Paper, No. 96-7. Ottawa: Bank of Canada.

DU TOIT, C.B. (1999). A Supply-side Model of the South African Economy: Critical Policy Implications, Unpublished Doctoral Thesis, Pretoria: University of Pretoria. AND T.J. DE WET, (2002). A Neoclassical Production Function for the South African Economy: Theory and Evidence. South African Journal of Economic and Management Sciences, SS No. 4:1-75.

ELMESKOV, J. AND M. MACFARLAN, (1993). Unemployment Persistence. OECD Economic Studies, No. 21. Paris: Organisation for Economic Co-operation and Development (OECD).

GIORNO, C., P. RICHARDSON, D. ROSEVEARE, AND P. VAN DEN NOORD, (1995). Estimating Potential Output, Output Gaps and Structural Balances. OECD Economics Department Working Papers, No. 152. Paris: Organisation for Economic Co-operation and Development (OECD).

HODRICK, R.J. AND E.C. PRESCOTT, (1997). Postwar U.S. Business Cycles: An Empirical Investigation. Journal of Money, Credit, and Banking, 29, 1-16

LAXTON, D. AND R. TETLOW, (1992). A Simple Multivariate Filter for the Measurement of Potential Output. Technical Report, No. 59. Ottawa: Bank of Canada.

NELSON, C.R. AND C. PLOSSER, (1982). Trend and Random Walks in Macro-economic Time Series. Journal of Monetary Economics, 10: 139-167.

PICHELMANN, K. AND A.U. SCHUH, (1997). The NAIRU-Concept: A Few Remarks. OECD Economics Department W orking Papers, No. 178. Paris: Organisation for Economic Co-operation and Development (OECD).

ROSE, D.E. (1988). The NAIRU in Canada: Concepts, Determinants and Estimates. Technical Report, No. 50. Ottowa: Bank of Canada.

SCACCIA VILLANI, F. AND P. SWA GEL, (1999). Measures of Potential Output: An Application to Israel. Working Paper, No. 104. Washington: International Monetary Fund (IMF).

SETTERFIELD, M., D. GORDON, D. AND L. OSBERG, (1992). Searching for a Will o' the Wisp: An Empirical Study of the NAIRU in Canada. European Economic Review, 36: 119-136.

TORRES, R. AND J.P. MARTIN, (1993). Potential Output in the Seven Major OECD Countries. OECD Economic Studies, No. 14. Paris: Organisation for Economic Co-operation and 
Development (OECD).

TURNER, D., P. RICHARDSON, AND S. RAUFFET, (1996). The Role of Real and Nominal

Rigidities in Macroeconomic Adjustment, OECD Economic Studies, No. 21. Paris:

Organisation for Economic Co-operation and Development (OECD). 